\title{
Taxonomic updates for the genus Gyrovirus (family Anelloviridae): recognition of several new members and establishment of species demarcation criteria
}

\author{
Simona Kraberger ${ }^{1} \cdot$ Tanja Opriessnig $^{2} \cdot$ Vladimir Celer $^{3} \cdot$ Fabrizio Maggi $^{4} \cdot$ Hiroaki Okamoto $^{5}$. \\ Anne-Lie Blomström ${ }^{6} \cdot$ Dániel Cadar $^{7} \cdot$ Balázs Harrach $^{8} \cdot$ Philippe Biagini $^{9} \cdot$ Arvind Varsani $^{1,10}$
}

Published online: 4 August 2021

(c) The Author(s), under exclusive licence to Springer-Verlag GmbH Austria, part of Springer Nature 2021

\begin{abstract}
The genus Gyrovirus was assigned to the family Anelloviridae in 2017 with only one recognized species, Chicken anemia virus. Over the last decade, many diverse viruses related to chicken anemia virus have been identified but not classified. Here, we provide a framework for the classification of new species in the genus Gyrovirus and communicate the establishment of nine new species. We adopted the 'Genus + freeform epithet' binomial system for the naming of these species.
\end{abstract}

The genus Gyrovirus was assigned to the family Anelloviridae in 2017 [20] to better align with the genomic properties of the viruses in this family. Like other members of the family Anelloviridae, gyroviruses have negative-sense single-stranded DNA genomes that contain at least three large open reading frames. As Chicken anemia virus [8] has been the sole species in the genus Gyrovirus, there have been no established guidelines for the classification of a new species within this genus. However, over the last decade, the nucleotide sequences of 49 genomes of viruses related to chicken anemia virus (CAV) have been determined from

Handling Editor: Sead Sabanadzovic.

Arvind Varsani

arvind.varsani@asu.edu

1 The Biodesign Center for Fundamental and Applied Microbiomics, Center for Evolution and Medicine, School of Life Sciences, Arizona State University, $1001 \mathrm{~S}$. McAllister Ave, Tempe, AZ 85287-5001, USA

2 The Roslin Institute and R(D)SVS, University of Edinburgh, Easter Bush, Midlothian EH25 9RG, Scotland, UK

3 Faculty of Veterinary Medicine, University of Veterinary Sciences Brno, Palackeho 1946, 61242 Brno, Czech Republic

4 Department of Medicine and Surgery, University of Insubria, 21100 Varese, Italy

5 Division of Virology, Department of Infection and Immunity, Jichi Medical University School of Medicine, 3311-1 Yakushiji, Shimotsuke-shi, Tochigi 329-0498, Japan various species (Elaphe carinata, Felis catus, Fulmarus glacialis, Gallus gallus, Homo sapiens, Hydrobates homochroa, Mustela putorius furo, and Myrmoderus ferrugineus) (Table 1) but have remained unclassified [3-6, 9-11, 15-17, 19, 23, 29-32].

Here, we provide a framework for the classification of viruses in the genus Gyrovirus. We extracted the large open reading frame (ORF) VP1 [22] sequences of gyroviruses (n $=229$ ) from full-genome sequences available in the GenBank database (including those of CAV, GenBank accessed on 6 July 2020) to determine the distribution of pairwise identity values using SDT v1.2 [14]. The plot of the distribution of the pairwise identity values (Fig. 1A) reveals a clear

6 Department of Biomedical Sciences and Veterinary Public Health, Swedish University of Agricultural Sciences, Uppsala, Sweden

7 WHO Collaborating Centre for Arbovirus and Haemorrhagic Fever Reference and Research, Bernhard Nocht Institute for Tropical Medicine, 20359 Hamburg, Germany

8 Veterinary Medical Research Institute, Hungária krt. 21, 1143 Budapest, Hungary

9 Equipe Biologie des Groupes Sanguins, UMR 7268 ADES, CNRS, EFS, Aix-Marseille Université, 27 Bd. Jean Moulin, 13005 Marseille, France

10 Structural Biology Research Unit, Department of Integrative Biomedical Sciences, University of Cape Town, Cape Town 7925, South Africa 
Table 1 Summary of the classification of new members of the genus Gyrovirus

\begin{tabular}{|c|c|c|c|c|c|c|}
\hline New gyrovirus species & Accession no. & $\begin{array}{l}\text { Exemplar virus for the } \\
\text { species }\end{array}$ & Host & Country/region & Isolation source & Publication \\
\hline Gyrovirus fulglal & KR137527 & Gyrovirus GyV8 & Fulmarus glacialis & USA & $\begin{array}{l}\text { Spleen and uro- } \\
\text { pygial gland } \\
\text { tissue }\end{array}$ & [10] \\
\hline \multirow[t]{29}{*}{ Gyrovirus galgal } & HM590588 & Avian gyrovirus 2 & Gallus gallus & Brazil & Serum & [19] \\
\hline & JQ690763 & - & Homo sapiens & China & Feces & Unpublished \\
\hline & KJ452213 & - & Mustela putorius furo & Hungary & Feces & [5] \\
\hline & KJ452214 & - & Mustela putorius furo & Hungary & Feces & {$[5]$} \\
\hline & KU168250 & - & Gallus gallus & Italy & Serum & Unpublished \\
\hline & KX708506 & - & Gallus gallus & China & Liver; spleen & [31] \\
\hline & KX708507 & - & Gallus gallus & China & Liver; spleen & [31] \\
\hline & KX708508 & - & Gallus gallus & China & Liver; spleen & {$[31]$} \\
\hline & KX708509 & - & Gallus gallus & China & Liver; spleen & [31] \\
\hline & KX708510 & - & Gallus gallus & China & Liver; spleen & [31] \\
\hline & KX708511 & - & Gallus gallus & China & Liver; spleen & [31] \\
\hline & KX708512 & - & Gallus gallus & China & Liver; spleen & {$[31]$} \\
\hline & KX708513 & - & Gallus gallus & China & Liver; spleen & [31] \\
\hline & KX708514 & - & Gallus gallus & China & Liver; spleen & [31] \\
\hline & KX708515 & - & Gallus gallus & China & Liver; spleen & [31] \\
\hline & KX708516 & - & Gallus gallus & China & Liver; spleen & [31] \\
\hline & KX708517 & - & Gallus gallus & China & Liver; spleen & [31] \\
\hline & KX708518 & - & Gallus gallus & China & Liver; spleen & [31] \\
\hline & KX708519 & - & Gallus gallus & China & Liver; spleen & {$[31]$} \\
\hline & KX708520 & - & Gallus gallus & China & Liver; spleen & [31] \\
\hline & KX708521 & - & Gallus gallus & China & Liver; spleen & [31] \\
\hline & KX708522 & - & Gallus gallus & China & Liver; spleen & [31] \\
\hline & KY039279 & - & Gallus gallus & Brazil & Feces & [11] \\
\hline & MG846492 & - & Gallus gallus & Brazil & Feces & [11] \\
\hline & MK089244 & - & Felis catus & China & Feces & [15] \\
\hline & MK089245 & - & Felis catus & China & Feces & [15] \\
\hline & MK089246 & - & Felis catus & China & Feces & [15] \\
\hline & MK840982 & - & Elaphe carinata & China & Liver & {$[30]$} \\
\hline & MT671981 & - & Gallus gallus & Brazil & muscle & [4] \\
\hline Gyrovirus galga2 & KM111536 & Gyrovirus GyV7-SF & Gallus gallus & USA & muscle & {$[32]$} \\
\hline \multirow[t]{7}{*}{ Gyrovirus homsal } & JQ308210 & Gyrovirus GyV3 & Homo sapiens & Chile & Feces & [16] \\
\hline & KM348009 & - & Mustela putorius furo & Hungary & Feces & [6] \\
\hline & MG366592 & - & Gallus gallus & China & Proventricular & [9] \\
\hline & MK089247 & - & Felis catus & China & Feces & [15] \\
\hline & MK089248 & - & Felis catus & China & Feces & {$[15]$} \\
\hline & MK089249 & - & Felis catus & China & Feces & [15] \\
\hline & MT671982 & - & Gallus gallus & Brazil & muscle & [4] \\
\hline \multirow[t]{3}{*}{ Gyrovirus homsa2 } & KF294862 & Gyrovirus Tu789 & Homo sapiens & Tunisia & Feces & [17] \\
\hline & MK089250 & - & Felis catus & China & Feces & [15] \\
\hline & MK089251 & - & Felis catus & China & Feces & {$[15]$} \\
\hline \multirow[t]{5}{*}{ Gyrovirus homsa3 } & JX310702 & Gyrovirus 4 & Homo sapiens & Hong Kong & Feces & [3] \\
\hline & KJ452215 & - & Mustela putorius furo & Hungary & Feces & {$[5]$} \\
\hline & KY024580 & - & Gallus gallus & Brazil & Feces & [11] \\
\hline & MG846493 & - & Gallus gallus & Brazil & Feces & [12] \\
\hline & MT671983 & - & Gallus gallus & Brazil & Muscle & [4] \\
\hline Gyrovirus homsa4 & KF294861 & Gyrovirus Tu243 & Homo sapiens & Tunisia & Feces & [17] \\
\hline
\end{tabular}


Table 1 (continued)

New gyrovirus species Accession no. Exemplar virus for the Hos species

\begin{tabular}{|c|c|c|c|c|c|c|}
\hline Gyrovirus hydhol & MH378452 & $\begin{array}{l}\text { Ashy storm petrel } \\
\text { gyrovirus }\end{array}$ & $\begin{array}{l}\text { Hydrobates homo- } \\
\text { chroa }\end{array}$ & USA & Cloacal swab & [29] \\
\hline Gyrovirus myferrl & MH638372 & Gyrovirus 11 & $\begin{array}{l}\text { Myrmoderus ferrug- } \\
\text { ineus }\end{array}$ & French Guiana & Cloacal swab & [23] \\
\hline
\end{tabular}

trough in the distribution between $67 \%$ and $92 \%$ pairwise identity. In a revision of the species demarcation criteria for members of the genus Anellovirus based on pairwise alignments (rather than global-alignment-derived pairwise identity scores) [28], we propose a species demarcation criterion of $69 \%$ based on the ORF1 coding open reading frame (ORF) of mammalian-infecting anelloviruses. To align species demarcation across the family Anelloviridae, we define a $69 \%$ VP1 nucleotide sequence pairwise identity threshold for species demarcation also for gyroviruses. Based on this, we establish nine new species to accommodate the 49 unclassified gyroviruses (Table 1). We provide further support for these species assignments using a colour-coded pairwise identity matrix and a midpoint-rooted maximum-likelihood phylogenetic tree of the VP1 nucleotide sequences (Fig. 1B and C).

For naming of the nine new species, we adopted the binomial "Genus + freeform epithet" species nomenclature outlined by Siddell et al. [21]. A summary of the 47 newly classified gyroviruses is provided in Table 1 .

We recommend the following guidelines for establishing new species within the genus Gyrovirus to align with what has been recommended previously for classification of viruses in the families Circoviridae [20], Geminiviridae [2, 13, 24, 25], Genomoviridae [26], and Smacoviridae [27] as well as single-stranded DNA satellite molecules in the family Alphasatellitidae [1]:

1. If the complete VP1 ORF of a new gyrovirus has $>69 \%$ nucleotide pairwise identity to that of any member assigned to a currently classified gyrovirus species, the virus belongs to that particular species.

a. In the event that the complete VP1 ORF of a new gyrovirus has $>69 \%$ nucleotide pairwise identity to those of members of more than one gyrovirus species, the virus should be considered a member of the species with whose members it shares the highest percentage VP1 pairwise identity.

b. In the event that the complete VP1 ORF of a new gyrovirus has $>69 \%$ nucleotide pairwise identity to those of one or more members assigned to a particular gyrovirus species, even if it shares $<69 \%$ identity with those of the majority of the members assigned to that particular gyrovirus species, the virus should nevertheless be considered a member of that particular species.

2. If the complete VP1 ORF of a new gyrovirus has $<69 \%$ nucleotide pairwise identity to those of all members of currently classified gyrovirus species, the virus should be considered a member of a new species.

We would like to highlight that different tools can yield different pairwise identity values, depending on how they are calculated. We recommend that true pairwise identity determination tools be used rather than those that infer pairwise identity values from multiple alignments. The latter generally tend to deflate the score due to gaps in the global multiple alignment and thus do not reflect the true pairwise identity between two sequences. 


\section{A}

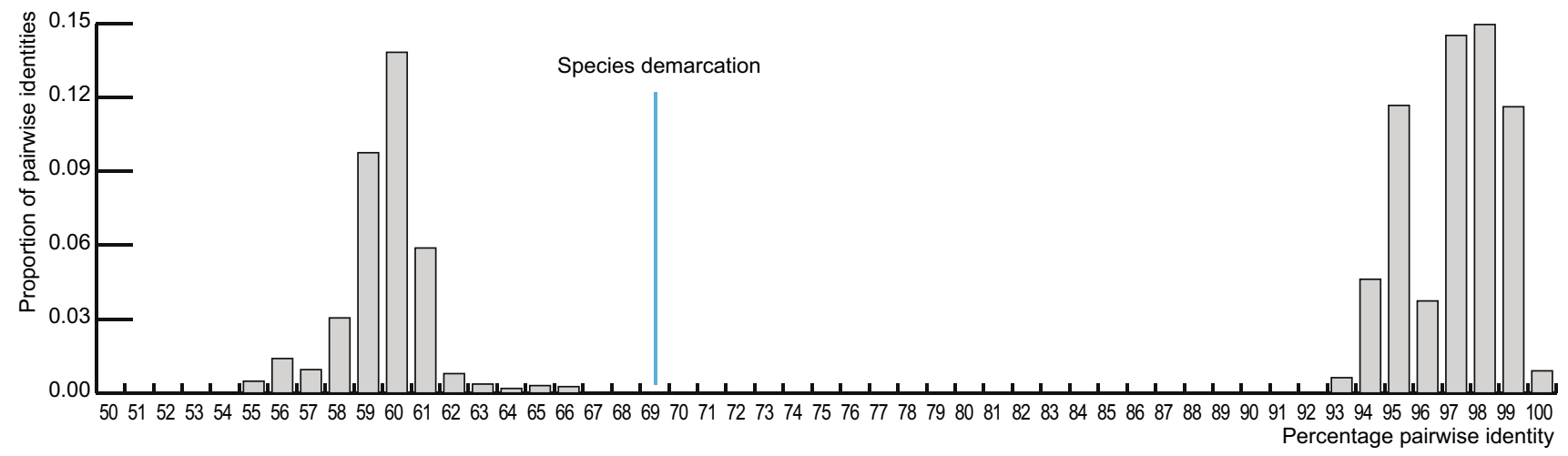

B
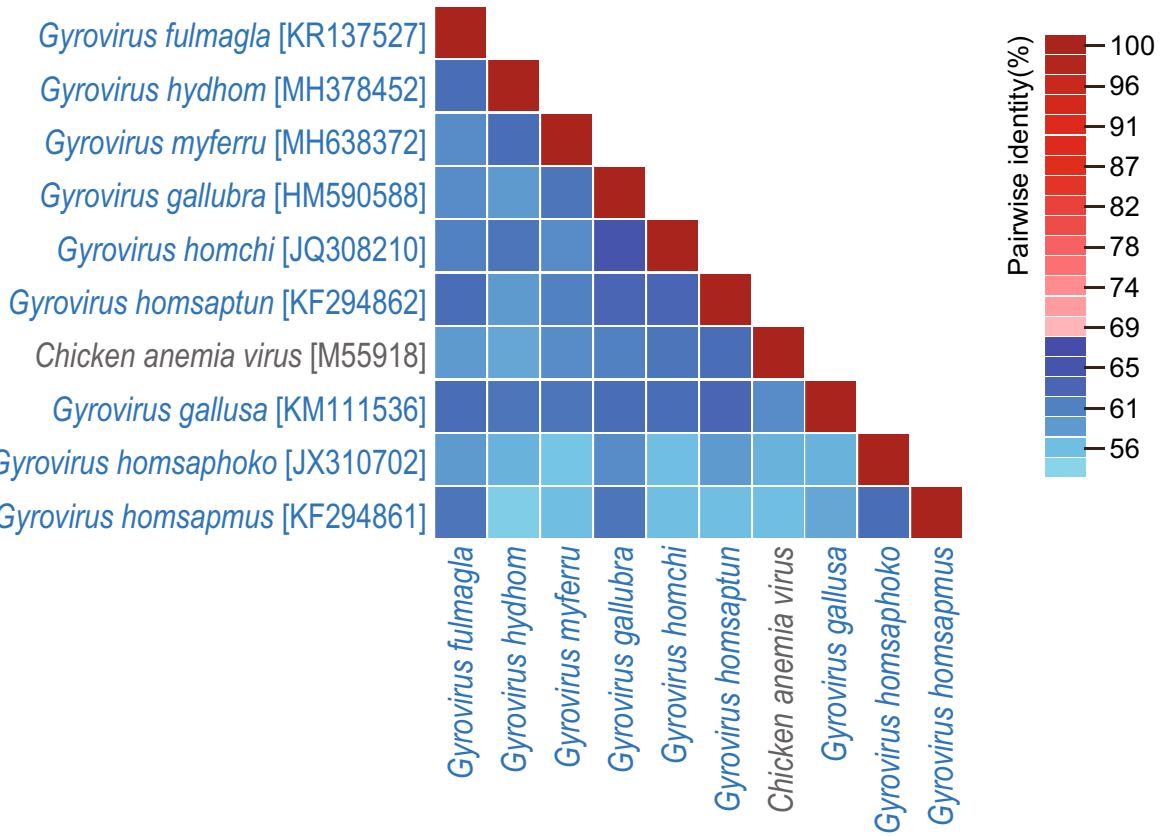

C

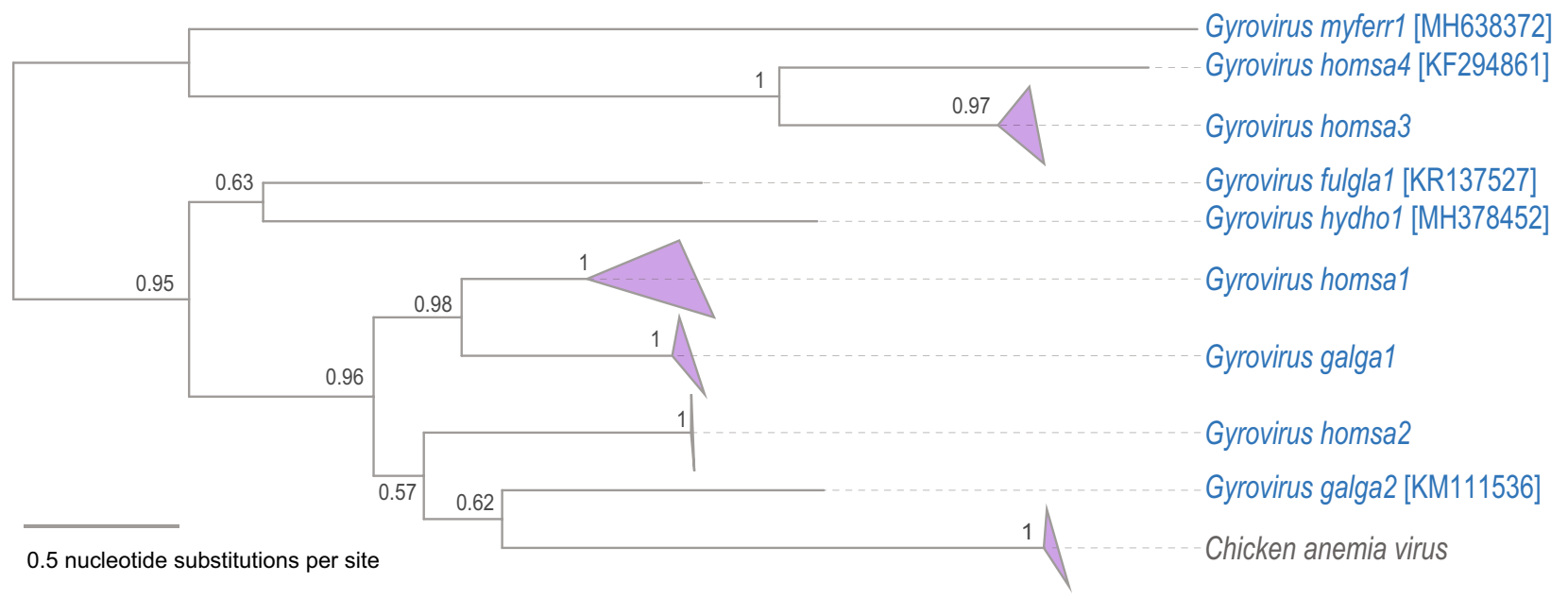


४Fig. 1 A Distribution of pairwise identity values for VP1 nucleotide sequences of gyroviruses available in the GenBank database ( $\mathrm{n}$ $=229$ ). $\mathbf{B}$ Pairwise identity matrix of representative sequences from each species inferred using SDT v1.2 [14]. C Maximum-likelihood phylogenetic tree of the aligned VP1 sequences of representative gyroviruses inferred using PHYML [7] with the GTR $+G$ model (determined using jModelTest) [18] and aLRT branch support. The tree is rooted at the midpoint. New species are shown in blue.

Acknowledgements B.H. is supported by the National Research, Development and Innovation Office-NKFIH (NN128309).

\section{Declarations}

Conflict of interest The authors declare no conflicts of interest.

\section{References}

1. Briddon RW, Martin DP, Roumagnac P, Navas-Castillo J, FialloOlive E, Moriones E, Lett JM, Zerbini FM, Varsani A (2018) Alphasatellitidae: a new family with two subfamilies for the classification of geminivirus- and nanovirus-associated alphasatellites. Arch Virol 163:2587-2600

2. Brown JK, Zerbini FM, Navas-Castillo J, Moriones E, RamosSobrinho R, Silva JC, Fiallo-Olive E, Briddon RW, HernandezZepeda C, Idris A, Malathi VG, Martin DP, Rivera-Bustamante R, Ueda S, Varsani A (2015) Revision of Begomovirus taxonomy based on pairwise sequence comparisons. Arch Virol 160:1593-1619

3. Chu DK, Poon LL, Chiu SS, Chan KH, Ng EM, Bauer I, Cheung TK, Ng IH, Guan Y, Wang D, Peiris JS (2012) Characterization of a novel gyrovirus in human stool and chicken meat. J Clin Virol 55:209-213

4. Cibulski S, Alves de Lima D, Fernandes Dos Santos H, Teixeira TF, Tochetto C, Mayer FQ, Roehe PM (2021) A plate of viruses: Viral metagenomics of supermarket chicken, pork and beef from Brazil. Virology 552:1-9

5. Feher E, Pazar P, Kovacs E, Farkas SL, Lengyel G, Jakab F, Martella V, Banyai K (2014) Molecular detection and characterization of human gyroviruses identified in the ferret fecal virome. Arch Virol 159:3401-3406

6. Feher E, Pazar P, Lengyel G, Phan TG, Banyai K (2015) Sequence and phylogenetic analysis identifies a putative novel gyrovirus 3 genotype in ferret feces. Virus Genes 50:137-141

7. Guindon S, Dufayard JF, Lefort V, Anisimova M, Hordijk W, Gascuel O (2010) New algorithms and methods to estimate maximum-likelihood phylogenies: assessing the performance of PhyML 3.0. Syst Biol 59:307-321

8. Kato A, Fujino M, Nakamura T, Ishihama A, Otaki Y (1995) Gene organization of chicken anemia virus. Virology 209:480-488

9. Li G, Yuan S, He M, Zhao M, Hao X, Song M, Zhang L, Qiao C, Huang L, Zhang L, Li C, Wang G, Cheng Z (2018) Emergence of gyrovirus 3 in commercial broiler chickens with transmissible viral proventriculitis. Transbound Emerg Dis 65:1170-1174

10. Li L, Pesavento PA, Gaynor AM, Duerr RS, Phan TG, Zhang W, Deng X, Delwart E (2015) A gyrovirus infecting a sea bird. Arch Virol 160:2105-2109

11. Lima DA, Cibulski SP, Finkler F, Teixeira TF, Varela APM, Cerva C, Loiko MR, Scheffer CM, Dos Santos HF, Mayer FQ, Roehe PM (2017) Faecal virome of healthy chickens reveals a large diversity of the eukaryote viral community, including novel circular ssDNA viruses. J Gen Virol 98:690-703

12. Lima DA, Cibulski SP, Tochetto C, Varela APM, Finkler F, Teixeira TF, Loiko MR, Cerva C, Junqueira DM, Mayer FQ, Roehe PM (2019) The intestinal virome of malabsorption syndromeaffected and unaffected broilers through shotgun metagenomics. Virus Res 261:9-20

13. Muhire B, Martin DP, Brown JK, Navas-Castillo J, Moriones E, Zerbini FM, Rivera-Bustamante R, Malathi VG, Briddon RW, Varsani A (2013) A genome-wide pairwise-identity-based proposal for the classification of viruses in the genus Mastrevirus (family Geminiviridae). Arch Virol 158:1411-1424

14. Muhire BM, Varsani A, Martin DP (2014) SDT: a virus classification tool based on pairwise sequence alignment and identity calculation. PLoS ONE 9:e108277

15. Niu JT, Yi SS, Dong GY, Guo YB, Zhao YL, Huang HL, Wang K, Hu GX, Dong H (2019) Genomic characterization of diverse gyroviruses identified in the feces of domestic cats. Sci Rep 9:13303

16. Phan TG, Li L, O'Ryan MG, Cortes H, Mamani N, Bonkoungou IJO, Wang C, Leutenegger CM, Delwart E (2012) A third gyrovirus species in human faeces. J Gen Virol 93:1356-1361

17. Phan TG, Vo NP, Sdiri-Loulizi K, Aouni M, Pothier P, AmbertBalay K, Deng X, Delwart E (2013) Divergent gyroviruses in the feces of Tunisian children. Virology 446:346-348

18. Posada D (2008) jModelTest: phylogenetic model averaging. Mol Biol Evol 25:1253-1256

19. Rijsewijk FA, Dos Santos HF, Teixeira TF, Cibulski SP, Varela AP, Dezen D, Franco AC, Roehe PM (2011) Discovery of a genome of a distant relative of chicken anemia virus reveals a new member of the genus Gyrovirus. Arch Virol 156:1097-1100

20. Rosario K, Breitbart M, Harrach B, Segales J, Delwart E, Biagini P, Varsani A (2017) Revisiting the taxonomy of the family Circoviridae: establishment of the genus Cyclovirus and removal of the genus Gyrovirus. Arch Virol 162:1447-1463

21. Siddell SG, Walker PJ, Lefkowitz EJ, Mushegian AR, Dutilh BE, Harrach B, Harrison RL, Junglen S, Knowles NJ, Kropinski AM, Krupovic M, Kuhn JH, Nibert ML, Rubino L, Sabanadzovic S, Simmonds P, Varsani A, Zerbini FM, Davison AJ (2020) Binomial nomenclature for virus species: a consultation. Arch Virol 165:519-525

22. Todd D, Creelan JL, Mackie DP, Rixon F, McNulty MS (1990) Purification and biochemical characterization of chicken anaemia agent. J Gen Virol 71(Pt 4):819-823

23. Truchado DA, Diaz-Piqueras JM, Gomez-Lucia E, Domenech A, Mila B, Perez-Tris J, Schmidt-Chanasit J, Cadar D, Benitez L (2019) A novel and divergent gyrovirus with unusual genomic features detected in wild passerine birds from a remote rainforest in French Guiana. Viruses 11:1148

24. Varsani A, Martin DP, Navas-Castillo J, Moriones E, HernandezZepeda C, Idris A, Murilo Zerbini F, Brown JK (2014) Revisiting the classification of curtoviruses based on genome-wide pairwise identity. Arch Virol 159:1873-1882

25. Varsani A, Navas-Castillo J, Moriones E, Hernandez-Zepeda C, Idris A, Brown JK, Murilo Zerbini F, Martin DP (2014) Establishment of three new genera in the family Geminiviridae: Becurtovirus, Eragrovirus and Turncurtovirus. Arch Virol 159:2193-2203

26. Varsani A, Krupovic M (2017) Sequence-based taxonomic framework for the classification of uncultured single-stranded DNA viruses of the family Genomoviridae. Virus Evol 3:vew037

27. Varsani A, Krupovic M (2018) Smacoviridae: a new family of animal-associated single-stranded DNA viruses. Arch Virol 163:2005-2015

28. Varsani A, Opriessnig T, Celer V, Maggi F, Okamoto H, Blomström A-L, Cadar D, Harrach B, Biagini P, Kraberger S (2021) Taxonomic update for mammalian anelloviruses (family Anelloviridae). Arch Virol. https://doi.org/10.1007/s00705-021-05192-x 
29. Waits K, Bradley RW, Warzybok P, Kraberger S, Fontenele RS, Varsani A (2018) Genome Sequence of a Gyrovirus Associated with Ashy Storm-Petrel. Microbiol Resour Announc 7:e00958-18

30. Wu Q, Xu X, Chen Q, Ji J, Kan Y, Yao L, Xie Q (2019) Genetic analysis of avian gyrovirus 2 variant-related gyrovirus detected in farmed king ratsnake (Elaphe carinata): the first report from China. Pathogens 8:185

31. Yao S, Gao X, Tuo T, Han C, Gao Y, Qi X, Zhang Y, Liu C, Gao H, Wang Y, Wang X (2017) Novel characteristics of the avian gyrovirus 2 genome. Sci Rep 7:41068
32. Zhang W, Li L, Deng X, Kapusinszky B, Delwart E (2014) What is for dinner? Viral metagenomics of US store bought beef, pork, and chicken. Virology 468:303-310

Publisher's Note Springer Nature remains neutral with regard to jurisdictional claims in published maps and institutional affiliations. 